\title{
CLINICAL PROFILE, PRESCRIPTION PATTERNS, AND ADVERSE DRUG REACTIONS IN PATIENTS WITH VITILIGO: A PROSPECTIVE STUDY
}

\author{
INDRANEEL $M^{1 *}$, GOVARDHAN $M^{1}$, KIRANMAYI T ${ }^{1}$, SNEHA REDDY PR ${ }^{1}$, SUREKHA ${ }^{2}$, DIVYA REKHA $0^{1}$, \\ RAM SHARAN T ${ }^{2}$, ANNA BALAJI ${ }^{3}$
}

${ }^{1}$ Department of Pharmacy Practice, Sree Vidyanikethan College of Pharmacy, Tirupati, Andhra Pradesh, India. ${ }^{2}$ Department of Dermatology, Venereology, and Leprosy, SVIMS/SPMC-W, Tirupati, Andhra Pradesh, India. ${ }^{3}$ Principal, Sree Vidyanikethan College of Pharmacy, Tirupati, Andhra Pradesh, India. Email: mannevaram.indraneel@gmail.com

\author{
Received: 29 December 2020, Revised and Accepted: 08 February 2021
}

\section{ABSTRACT}

Objectives: The objectives of the study were to assess clinical profile (age of onset, age of presentation, gender, site of involvement, severity (stage), type of vitiligo, triggering factors, and associated diseases), prescription patterns (monotherapy, combination therapy, oral, topical, and therapeutic categories of drugs prescribed) and to monitor and report adverse drug reactions (based on World Health Organization [WHO] causality assessment scale) in vitiligo patients.

Methods: A hospital-based prospective observational study was carried out by evaluating and assessing the clinical profile and prescription patterns of 85 patients who attended dermatology venereology and leprosy (DVL) outpatient department at Sri Padmavathi Medical College for Women, SVIMS, Tirupati, over a period of 6 months from June 2019 to December 2019.

Results: In our study, forty four (51.77\%) patients were female, vitiligo vulgaris is the most common morphological type observed in twenty seven (31.76\%) patients. 31-50 years was the predominant age group. The mean age of onset and presentation was 38.35 (standard deviation of 18.37) and 43.27 (standard deviation of 17.96) years, respectively. Forty-one (48.23\%) patients were having Stage 1 vitiligo. Fifty (58.85\%) patients were having vitiligo at more than 1 site. Twelve (14.11\%) patients were having a positive family history of vitiligo. Thirty-seven (43.53\%) patients had triggering factors. Associated diseases were found in thirty (35\%) patients. Combination therapy was given to sixty one (71.77\%) patients. Topical medications were given to fifty two (61.18\%) patients. During the study, we did not have a single patient complaining of any adverse drug reaction.

Conclusion: Longer the time after appearance of vitiligo, lesser the number of patients attending follow-up. If vitiligo is diagnosed at the earliest stage, more are the chances for complete repigmentation. Patients with a poor economic background are less bothered about their skin condition and are not using medications properly.

Keywords: Clinical profiles, Prescription patterns, Vitiligo.

(c) 2021 The Authors. Published by Innovare Academic Sciences Pvt Ltd. This is an open access article under the CC BY license (http://creativecommons.org/ licenses/by/4.0/) DOI: http://dx.doi.org/10.22159/ajpcr.2021v14i4.40658. Journal homepage: https://innovareacademics.in/journals/index.php/ajpcr

\section{INTRODUCTION}

Vitiligo is a psychologically debilitating and disfiguring disease with localized depigmentation occurring due to progressive loss of melanocytes [1] and is characterized by milky white sharply demarcated macules affecting the people of any age, gender, and ethnicity [2] and it has a major impact on patient's quality of life and may negatively affect the sexual relationship. Patients may experience a number of psychological conditions such as shame, depression, and anxiety which lead to low self-esteem and social isolation [1].

As data are scarce regarding the clinical profile and prescription patterns of vitiligo in South India, therefore, this study aimed to examine the clinical profile (age of onset, age of presentation, gender, site of distribution, severity (stage), type of vitiligo, triggering factors, and associated diseases), prescription patterns (monotherapy, combination therapy, oral, topical, and therapeutic categories of drugs prescribed), and adverse drug reactions in vitiligo patients based on the WHO causality assessment scale presenting to the dermatology venereology and leprosy (DVL) outpatient department (OPD) of Sri Venkateswara Institute of Medical Sciences (SVIMS), Tirupati, Andhra Pradesh, India.

\section{METHODS}

Study design and ethical consideration

A hospital-based prospective observational study on the assessment and monitoring of clinical profile, prescription patterns, and adverse drug reactions of vitiligo patients in the dermatology outpatient department was conducted in a tertiary care teaching hospital "Sri Venkateswara Institute of Medical Sciences," Tirupati, Andhra Pradesh, India, in 2019. The ethical clearance was obtained from the Institutional Ethics Committee with approved IEC NO. 921 from Sri Venkateswara Institute of Medical Sciences and after obtaining informed consent from the subjects.

\section{Inclusion criteria}

Patients who were diagnosed with vitiligo and willing to participate were considered for inclusion in the study. Pregnant women and children were also included in the study.

\section{Exclusion criteria}

The following criteria were excluded from the study:

- Patient not willing to participate in the study

- Patients with other depigmentary disorders.

\section{Sample size}

Eighty-five patients diagnosed with vitiligo were taken as sample size and examined as per study guidelines.

\section{Method of collection of data}

On the day of the examination, all participants were taken informed consent. Patient's case sheets were analyzed for details such as age, gender, diagnosis, and comorbid conditions. Besides, we have also assessed the prescription patterns and checked for adverse drug reactions. 
Statistical analysis

The data were collected and recorded in a pre-designed proforma and managed using Microsoft Excel worksheet during the final analysis. Descriptive statistics were done for all data and were reported in terms of mean values and percentages. All the data were assessed and compared using pie diagrams, graphs, and bar diagrams.

\section{RESULTS}

A total number of 85 vitiligo patients were included in the study.

Data evaluation based on age- and gender-wise distribution Out of 85 subjects, $51.77 \%$ were female $(n=44)$ and $48.23 \%$ were male $(n=41)$. The majority of subjects were under the age group of $31-50$ years $(n=31)$ constituting $36.4 \%$ followed by age group of $51-70(n=25)$ constituting of $29.4 \%$ and age group $11-30$ years $(n=23)$ constituting of $27 \%$ and least were observed in the age group of $<10$ years $(n=1)$ constituting of $1.17 \%$ of total subjects $(\mathrm{N}=85)$ (Table 1$)$.

Data evaluation based on age of onset of vitiligo

The onset of vitiligo is more prevalent in the age group of 31-50 years $(n=37)$ constituting $43.5 \%$ and less prevalence in the age group of $<10$ years $(n=6)$ which constitutes $7 \%$ (Table 2).

\section{Data evaluation based on types of vitiligo}

In our study, vitiligo vulgaris is observed in more number of patients 27 (31.76\%) followed by focal vitiligo 18 (21.17\%), acrofacial vitiligo 14 (16.47\%), mucosal vitiligo 13 (15.29\%), segmental vitiligo 06 (7.05\%), mixed vitiligo 06 (7.05\%), and vitiligo universalis 01 (1.17\%) (Fig. 1)

\section{Distribution of data based on stages of vitiligo}

In our study, we have observed more number of patients with Stage 1 vitiligo. Forty-one (48.23\%) had come to seek medical attention than other stages which reveals that patients were quick to spot any minor changes related to skin and wanted to get rid of it as quickly as possible

Table 1: Age- and gender-wise distribution of vitiligo patients

\begin{tabular}{llll}
\hline Age (years) & $\begin{array}{l}\text { Male } \\
\mathbf{n = 4 1}\end{array}$ & $\begin{array}{l}\text { Female } \\
\mathbf{n = 4 4} \\
\mathbf{( 4 8 . 2 3 \% )}\end{array}$ & $\begin{array}{l}\mathbf{( 5 1 . 7 7 \% )} \\
\mathbf{n}=\mathbf{8 5} \\
\mathbf{( \% )}\end{array}$ \\
\hline$<10$ & 0 & $1(2.27)$ & $1(1.17)$ \\
$11-30$ & $11(26.82)$ & $12(27.27)$ & $23(27.05)$ \\
$31-50$ & $13(31.70)$ & $18(40.90)$ & $31(36.48)$ \\
$51-70$ & $14(34.14)$ & $11(25)$ & $25(29.42)$ \\
$71-90$ & $3(7.33)$ & $2(4.54)$ & $5(5.88)$ \\
\hline
\end{tabular}

Table 2: Age of onset of vitiligo

\begin{tabular}{|c|c|c|c|}
\hline \multirow[t]{2}{*}{ Age (years) } & \multirow{2}{*}{$\begin{array}{l}\text { Male }(\%) \\
n=41\end{array}$} & \multirow{2}{*}{$\begin{array}{l}\text { Female (\%) } \\
n=44\end{array}$} & \multirow{2}{*}{$\begin{array}{l}\text { Number of } \\
\text { patients } \\
n=85(\%)\end{array}$} \\
\hline & & & \\
\hline$<10$ & $4(9.75)$ & $2(4.54)$ & $6(7.05)$ \\
\hline $11-30$ & 11 (26.83) & $12(27.27)$ & $23(27.05)$ \\
\hline $31-50$ & $16(39.03)$ & 21 (47.75) & $37(43.54)$ \\
\hline $51-70$ & $9(21.95)$ & $7(15.90)$ & $16(18.84)$ \\
\hline $71-90$ & $1(2.44)$ & $2(4.54)$ & $3(3.52)$ \\
\hline
\end{tabular}

Table 3: Triggering factors of vitiligo

\begin{tabular}{lll}
\hline Triggering factor & No. of patients (85) & Percentage (\%) \\
\hline Autoimmune disorders & 6 & 7.06 \\
Stress & 5 & 5.88 \\
Hypothyroidism & 3 & 3.53 \\
Trauma & 8 & 9.41 \\
Chemical exposure & 3 & 3.53 \\
Heredity & 12 & 14.11 \\
No factors & 48 & 56.47 \\
\hline
\end{tabular}

to prevent further deterioration. After Stage 1 patients, Stage 2 patients were more 21 (24.70\%), followed by Stage 4 patients 11 (12.94\%), Stage 3 patients 7 (8.23\%), and Stage 5 patients 5 (5.90\%) (Fig. 2).

\section{Distribution of data based on site of vitiligo}

In our study, it was clearly evident that vitiligo at more than 1 site 50 (58.85\%) is observed in most of the patients (Fig. 3).

\section{Triggering factors of vitiligo}

Majority of the patients $12(14.11 \%)$ had a positive family history followed by trauma $8(9.41 \%)$. Nearly $44 \%$ of patients were having triggering factors involved in our study (Table 3 ).

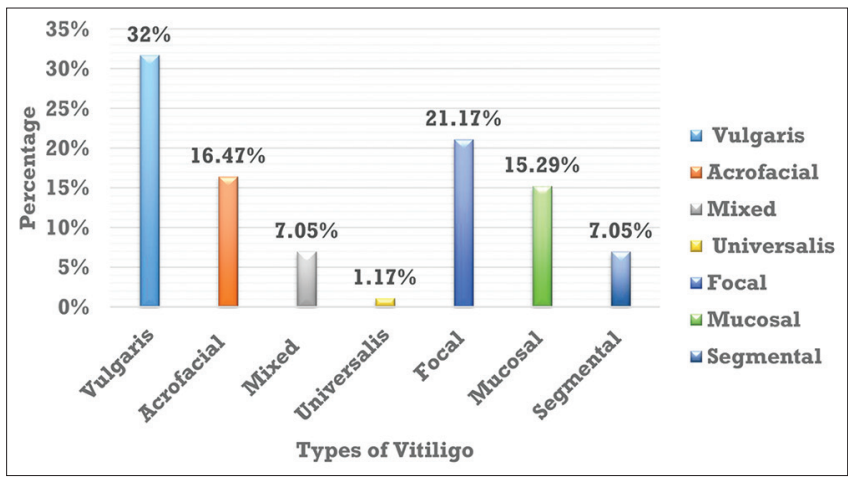

Fig. 1: Distribution of types of vitiligo

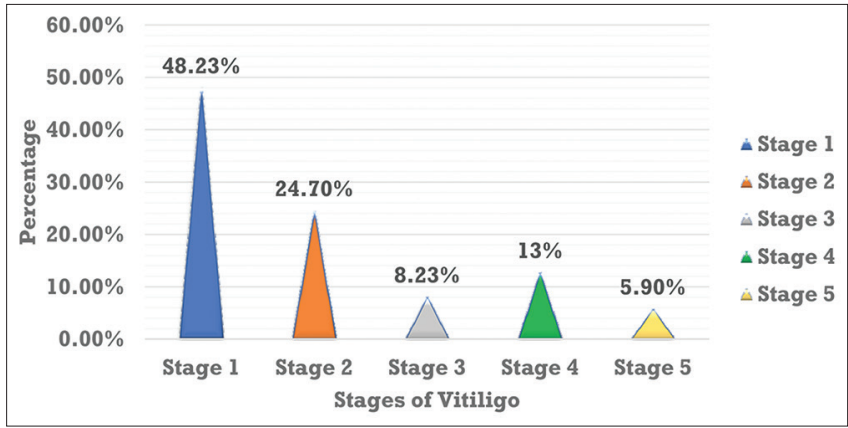

Fig. 2: Distribution of data based on stages of vitiligo

Table 4: Comorbid conditions observed in vitiligo patients

\begin{tabular}{lll}
\hline Associated diseases & Total & Percentage \\
\hline Diabetes mellitus & 4 & 4.7 \\
Psoriasis & 3 & 3.5 \\
Hypertension & 2 & 2.35 \\
Rheumatoid arthritis & 2 & 2.35 \\
Pernicious anemia & 1 & 1.18 \\
Pharyngitis & 1 & 1.18 \\
Bronchial asthma & 1 & 1.18 \\
Prostatomegaly & 1 & 1.18 \\
Hodgkin's disease & 1 & 1.18 \\
Myalgia & 1 & 1.18 \\
Coronary artery disease & 1 & 1.18 \\
Spondylosis & 1 & 1.18 \\
HTN+CAD & 2 & 2.35 \\
HTN+Nephrotic syndrome & 1 & 1.18 \\
PA+HTN+CAD+PM+BA & 1 & 1.18 \\
PA+DM+Hypoadrenalism+Hypothyroidism & 1 & 1.18 \\
HoT+Osteoporosis & 1 & 1.18 \\
DM+HTN & 2 & 2.35 \\
DM+HTN+HoT & 1 & 1.18 \\
DM+HoT & 1 & 1.18 \\
Lichen planus+Actinic cheilitis & 1 & 1.18 \\
No associated diseases & 55 & 64.7 \\
\hline
\end{tabular}

HTN: Hypertension, CAD: Coronary Artery Disease, PA: Pernicious Anemia, PM: Prostatomegaly, BA: Bronchial Asthma, HoT: Hypothyroidism 
Comorbid conditions observed in vitiligo patients

Majorly diabetes mellitus (10.58\%) and hypertension $(10.58 \%)$ were associated in more number of vitiligo patients, followed by psoriasis, hypothyroidism, and anemia (Table 4).

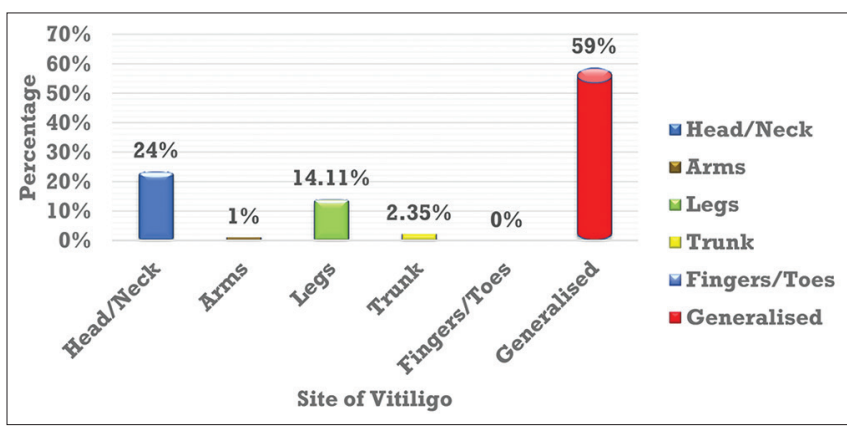

Fig. 3: Distribution of data based on site of vitiligo

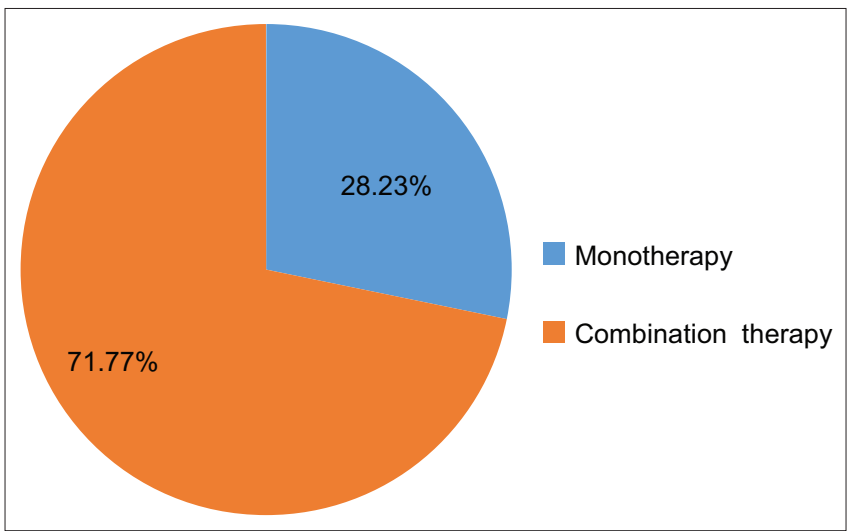

Fig. 4: Prescription patterns - Therapy

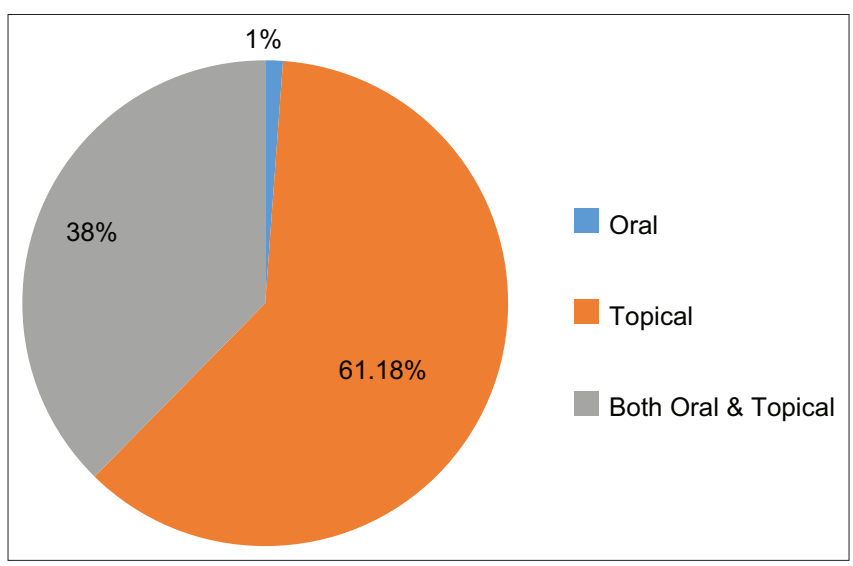

Fig. 5: Prescription patterns - Dosage forms

\section{Table 5: Therapeutic category of drugs prescribed to vitiligo}

\begin{tabular}{llll}
\hline S. No. & Therapeutic categories of drugs & Total & Percentages \\
\hline 1. & Topical corticosteroids & 69 & 34.5 \\
2. & Topical calcineurin inhibitors & 55 & 27.5 \\
3. & Human placental extract & 16 & 8 \\
4. & Decapeptide lotion & 12 & 6 \\
5. & Topical calcipotriol & 4 & 2 \\
6. & Topical psoralens & 3 & 1.5 \\
7. & Oral psoralens & 11 & 5.5 \\
8. & Oral corticosteroids & 2 & 1 \\
9. & Other orals (Vitamins and antioxidants) & 28 & 14 \\
\hline
\end{tabular}

Prescription patterns based on therapy

Combination therapy was given to most number of patients 61 (71.77\%). Monotherapy was given to only those patients $24(28.23 \%)$ who had very less depigmentation (Fig. 4)

\section{Prescription pattern based on dosage forms}

Majority of patients were given topical medications (61.18\%) followed by both oral and topical (37.64\%) and oral medications were given only to 1 patient (1.18\%) (Fig. 5).

\section{Therapeutic category of drugs prescribed to vitiligo}

Corticosteroids were prescribed to more number of patients $(34.5 \%)$ than calcineurin inhibitors (27.5\%). Topical psoralens were given to the least number of patients (1.5\%). In children, topical tacrolimus showed good results than corticosteroids (Tables 5 and 6).

\section{Patients - Follow-up}

Only 17 (20\%) patients attended for follow-up and majority of them were Stage 1 patients and they had seen improvement after treatment. When other patients were enquired on phone for the reason for their non-arrival, most common reason was less repigmentation is observed (Table 7).

\section{DISCUSSION}

A total of 85 patients were enrolled in our study but only one out of five patients turned for follow-up. The majority of patients missed the follow-up, when patients were called to know the reason for not turning up, we've got varying reasons from patients such as the hospital is far from their native place, cost of drugs is high, and very slow recovery rate. The most common one was less repigmentation after a few weeks ( $<4$ weeks) of treatment. Here, patients were expecting results even before the completion of the whole treatment duration. However, there is a significant improvement observed in Stage- 1 patients who had taken treatment immediately, so they've turned for follow-up multiple times.

Slight female predominance was observed in our study with male:female ratio of 1:1.07 and same results were obtained from similar types of studies by Fatani et al. in Saudi Arabia and Turkey but our results were contrasting to that of Chinthaamani $[11,12]$.

In our study, vitiligo vulgaris is observed in a greater number of patients (31.76\%) followed by focal vitiligo (21.17\%), acrofacial vitiligo (16.47\%), mucosal vitiligo (15.29\%), segmental vitiligo (7.05\%), mixed vitiligo (7.05\%), and vitiligo universalis $(1.17 \%)$. However, similar studies in North India conducted by Agarwal et al. showed that a greater number of patients were having acrofacial vitiligo (44\%). This shows contrasting epidemiological data between the north and south states of India [13].

About $43.51 \%$ of patients were suffering from localized vitiligo when compared to $56.49 \%$ of patients from generalized vitiligo which is in contrast to the study conducted by Fatani et al. in Saudi Arabia and Turkey which had $60.7 \%$ of localized vitiligo and $39.3 \%$ of patients suffering from generalized vitiligo [11].

The predominance of patients in 31-50 years age group (36.48\%) was observed. It attributed to the fact that this age group people are more concerned about their appearance in public and are more likely to seek medical attention which supports the study of Chinthaamani which had $35.33 \%$ of patients of similar age group [12].

The mean age of onset in our study was 38.35 years with a standard deviation of 18.37. The mean age of onset for Fatani et al. study in Saudi Arabia and Turkey was 24 years and a study by Mahajan et al. in North India had a mean age of onset of 20.5 years $[11,14]$

The mean age of presentation was 43.27 years with a standard deviation of 17.96 
Table 6: Line of treatment and drugs used in vitiligo

\begin{tabular}{|c|c|c|c|c|c|}
\hline \multicolumn{6}{|c|}{ Treatment chart [3-10] } \\
\hline S. No. & Treatment & Topical & Physical & Systemic & Surgical \\
\hline 1 & First line & $\begin{array}{l}\text { - Corticosteroids } \\
\text { - Clobetasol propionate - } 0.05 \% \\
\text { - Betamethasone } \\
\text { dipropionate - } 0.05 \% \\
\text { - Diflorasone diacetate - } 0.05 \% \\
\text { - Halobetasol propionate - } 0.05 \% \\
\text { - Amcinonide - } 0.1 \% \\
\text { - Betamethasone valerate - } 0.1 \% \\
\text { - Desoximetasone - } 0.25 \% \\
\text { - Fluocinolone acetonide - } 0.2 \% \\
\text { - Halocinonide - } 0.1 \% \\
\text { - Triamcinolone acetonide - } 0.5 \% \\
\text { - Fluticasone - } 0.01 \% \\
\text { - Hydrocortisone - } 0.1 \% \\
\text { - Calcineurin inhibitors } \\
\text { - Tacrolimus - } 0.03 \%, 0.1 \% \\
\text { - Pimecrolimus - } 1 \%\end{array}$ & $\begin{array}{l}\text { - Ultraviolet-B } \\
\text { (narrowband) } \\
\text { - Psoralen and } \\
\text { ultraviolet-A } \\
\text { light } \\
\text { (PUVA) }\end{array}$ & $\begin{array}{l}\text { - Janus kinase } \\
\text { Inhibitor: Tofacitinib - } 5 \text { mg } \\
\text { - Antioxidants }\end{array}$ & \\
\hline 2 & Second line & $\begin{array}{l}\text { - Calcipotriol - } 0.005 \% \\
\text { - Tacalcitol - } 20 \mathrm{mcg} / \mathrm{gm} \\
\text { - Decapeptide - } 1 \mathrm{mg} / \mathrm{ml} \\
\text { - Placental extract } \\
\text { - Complete depigmentation } \\
\text { - } 20 \% \text { Monobenzyl ether of } \\
\text { hydroquinone }\end{array}$ & $\begin{array}{l}\text { - Topical PUVA } \\
\text { - Excimer laser }\end{array}$ & $\begin{array}{l}\text { - Pulse Therapy } \\
\text { - Prednisolone -0.3mg/kg } \\
\text { - Methyl prednisolone - } \\
0.8 \mathrm{mg} / \mathrm{kg} \text { (max } 32 \mathrm{mg} \text { ) } \\
\text { - Betamethasone/ } \\
\text { Dexamethasone - } \\
2.5 \mathrm{mg} / \text { day } \\
\text { - Cyclophosphamide - } \\
50 \mathrm{mg} \text { with betamethasone }\end{array}$ & $\begin{array}{l}\text { - Grafting } \\
\text { - Mini-grafting } \\
\text { - Epidermal grafting } \\
\text { - Thin dermal - epidermal } \\
\text { grafting } \\
\text { - Non-cultured epidermal } \\
\text { suspension } \\
\text { - Melanocyte } \\
\text { transplantation }\end{array}$ \\
\hline
\end{tabular}

Table 7: Patients - Follow-up

\begin{tabular}{lll}
\hline Follow-up & No. of patients (85) & Percentage \\
\hline Turned up & 17 & 20 \\
Did not turn up & 68 & 80 \\
\hline
\end{tabular}

In our study, we have observed that more number of patients with Stage 1 vitiligo (48.23\%) had come to seek medical attention than other stages which reveals that patients were quick to spot any minor changes related to skin and wanted to get rid of it as quickly as possible to prevent further deterioration. Stage 1 patients who persisted with treatment had partial to complete repigmentation. After Stage 1 patients, Stage 2 patients were more in number (24.70\%).

In our study, it was clearly evident that vitiligo at more than 1 site $(58.85 \%)$ is observed in most of the patients. It supported a similar study done by Vora [15].

In our study, the majority of the patients (14.11\%) had a positive family history followed by trauma $(9.41 \%)$. Stress $(\sim 6 \%)$ also plays an important role in triggering vitiligo. Nearly $44 \%$ of patients were having triggering factors involved in our study to that of $33 \%$ of patients having triggering factors in a study by Mahajan et al. [14].

Majorly diabetes mellitus (10.58\%) and hypertension (10.58\%) were associated in a greater number of vitiligo patients, followed by psoriasis, hypothyroidism, and anemia.

Combination therapy was given to the greatest number of patients (71.77\%). Here, combination was given to patients who did not get repigmentation after using monotherapy. Monotherapy was given to only those patients who had very less depigmentation.

Majority of patients were given topical medications (61.18\%) followed by both oral and topical (37.64\%) and only oral medications were given to 1 patient (1.18\%).
Topical corticosteroids were prescribed to a greater number of patients $(34.5 \%)$ than calcineurin inhibitors $(27.5 \%)$. Oral psoralens and oral corticosteroids were given to $5.5 \%$ and $1 \%$ of patients, respectively. In children, topical tacrolimus showed good results than corticosteroids [16].

Corticosteroids were prescribed more to adult patients who had a recent onset of vitiligo followed by calcineurin inhibitors. Patients who were initially given corticosteroids, if they did not respond to treatment, during follow-up, they were given calcineurin inhibitors or the regimen was changed to either oral mini-pulse therapy or with the combination of topical calcipotriol for better results $[16,17]$.

During the whole study duration, we did not have a single patient complaining of any ADR, as all the doses, drugs were prescribed by taking all the patient's factors and history into consideration by the dermatologist.

\section{Limitations of the study}

- Majority of patients did not attend follow-up

- Patients were non-adherent to medications.

- Surgical treatments were not done for any patient.

\section{CONCLUSION}

The present study is focused on assessing and monitoring clinical profiles, prescription patterns, and adverse drug reactions in vitiligo patients. If vitiligo is diagnosed at the earliest stage, more are the chances for complete repigmentation. Longer the time after the appearance of vitiligo, lesser the number of patients attending followup. Patients with a poor economic background are less bothered about their skin condition and are not using medications properly. Stress will provoke vitiligo, so patients should attend some awareness programs to reduce stress which may help in controlling the progression of vitiligo to a certain extent.

Vitiligo remission is a very slow process. For Patients... To yield good results... Patience, persistence with treatment is required. 


\section{CONTRIBUTION OF AUTHORS}

Indraneel Mannevaram collected the data, performed the analysis, and wrote the paper. Govardhan Reddy Mukka collected the data, performed the analysis, and wrote the paper. Kiranmayi Thota collected the data, performed the analysis, and wrote the paper. Sneha Reddy Panchangam collected the data, performed the analysis, and wrote the paper. Dr. Surekha A conceived and designed the analysis, Divya Rekha Oddepalli conceived and designed the analysis, Dr. T. Ram Sharan M.D., fruitful discussions, suggestions in the manuscript. Anna Balaji, fruitful discussions, suggestions in the manuscript.

\section{CONFLICTS OF INTEREST}

We have no conflicts of interest to disclose.

\section{AUTHORS' FUNDING}

No external funding

\section{REFERENCES}

1. Available from: https://www gponline.com/managementpatientsvitiligo/dermatology/article/1373737. [Last accessed on 2021 Jan 19].

2. Bishnoi A, Parsad D. Clinical and molecular aspects of vitiligo treatments. Int J Mol Sci 2018;19:1509.

3. Falabella R, Barona MI. Update on skin repigmentation therapies in vitiligo. Pigment Cell Melanoma Res 2009;22:42-65.

4. Felsten LM, Alikhan A, Petronic V Rosic. Vitiligo: A comprehensive overview Part II: Treatment options and approach to treatment. J Am Acad Dermatol 2011;65:493-514.

5. Taieb A, Alomar A, Böhm M, Dell'anna ML, De Pase A,
Eleftheriadou V, et al. Guidelines for the management of vitiligo: The European dermatology forum consensus. Br J Dermatol 2013;168:5-19.

6. Mandel AS, Haberman HF, Pawlowski D, Goldstein E. Non-PUVA nonsurgical therapies for vitiligo. Clin Dermatol 1997;15:907-19.

7. Kanwar AJ, Kumaran MS. Childhood vitiligo: Treatment paradigms. Indian J Dermatol 2012;57:466-74.

8. Falabella R. Surgical approaches for stable vitiligo. Dermatol Surg 2005;31:1277-84.

9. Boone B, Ongenae K, Van Geel N, Vernijns S, De Keyser S, Naeyaert JM, et al. Topical pimecrolimus in the treatment of vitiligo. Eur J Dermatol 2007; 17:55-61.

10. Natta R, Somsak T, Wisuttida T, Laor L. Narrowband ultraviolet B radiation therapy for recalcitrant vitiligo in Asians. J Am Acad Dermatol 2003;49:4736

11. Fatani MI, Aldhahri RM, Otaibi HO, Kalo BB, Khalifa MA. Acknowledging popular misconceptions about vitiligo in Western Saudi Arabia. J Dermatol Dermatol Surg 2016;20:27-31.

12. Chinthaamani KP. An epidemiological study of vitiligo in an urban city hospital. Acta Sci Med Sci 2018;24:07-12.

13. Agarwal S, Ojha A, Gupta S. Profile of vitiligo in kumaun region of Uttarakhand, India. Indian J Dermatol 2014;59:209.

14. Mahajan VK, Vashist S, Chauhan PS, Mehta KIS, Sharma V, Sharma A. Clinico-epidemiological profile of patients with vitiligo: A retrospective study from a tertiary care center of north India. Indian Dermatol Online J 2019;10:38-44.

15. Vora RV, Patel BB, Chaudhary AH, Mehta MJ, Pilani AP. A clinical study of vitiligo in a rural set up of Gujarat. Indian J Community Med 2014;39:143-46.

16. Wazir SM, Paracha MM, Khan SU. Efficacy and safety of topical mometasone furoate $0.01 \%$ vs. tacrolimus $0.03 \%$ and mometasone furoate 0.01\%in vitiligo. J Pak Assoc Dermatol 2016;20:89-92.

17. Kumaran MS, Kaur I, Kumar B. Effect of topical calcipotriol, betamethasone dipropionate, and their combination in the treatment of localized vitiligo. J Eur Acad Dermatol Venereol 2006;20:269-73. 